\title{
Potential Use of Eggshell as Bone Graft Compared with Bovine for Bone Defect: A Systematic Review Study
}

\author{
Hanif Andhika Wardana ${ }^{1}$, Mujaddid Idulhaq ${ }^{2}$ D, Rhyan Darma Saputra ${ }^{3}$, Rieva Ermawan ${ }^{3}$, Musa Fasa Roshada ${ }^{1 *}$ (D) \\ ${ }^{1}$ Department of Orthopaedic and Traumatology, Faculty of Medicine, Sebelas Maret University, Surakarta, Indonesia; ${ }^{2}$ Candidate \\ of Doctorate Program, Faculty of Medicine, Sebelas Maret University, Surakarta, Indonesia; ${ }^{3}$ Department of Orthopaedic and \\ Traumatology, Faculty of Medicine, Sebelas Maret University, Moewardi General District Hospital, Surakarta, Indonesia
}

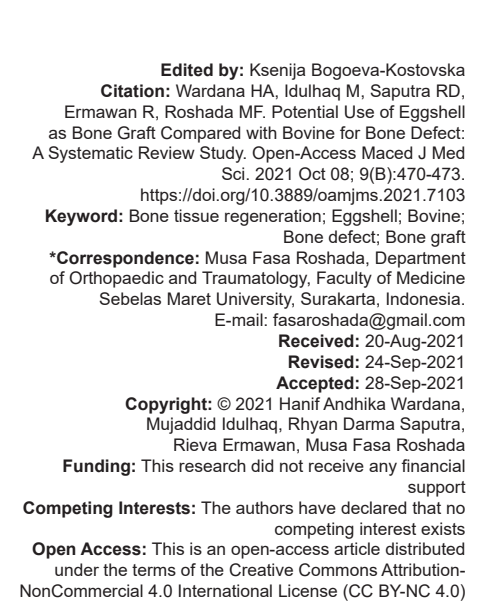

\section{Abstract}

BACKGROUND: The use of bone graft in the management of bone defect is a challenge in the world of orthopedics Recently, eggshell containing hydroxyapatite $(\mathrm{HA})$ has become a new hope in the use of an economical and efficient bone graft in the treatment of bone defects.

AIM: The aim of this systematic review was to explore the available literature on the clinical performance of eggshells as bone grafts in guided bone regeneration.

METHOD: Two data resources (PubMed and Cochrane) were searched from January 2010 to September 2020 Clinical trials using eggshells as bone grafts were included in the review. Animal and in vivo studies were excluded from the review.

RESULTS: A total of 202 studies were taken, then screened and 15 studies finally included. Clinical and radiological evaluations show complete recovery after the procedure. Comparison with synthetic HA shows similar healing characteristics.

CONCLUSION: Eggshell compared to bovine as bone graft showed no difference in bone healing. Within the limitations of the included studies, eggshells can be used safely and efficiently in integrated bone regeneration procedures.

\section{Introduction}

Bone defect is a serious condition that occurs after a pathological process has damaged vital components of bone. This condition is characterized by a lack or loss of bone tissue which will affect the function of the bones to support the body. Bone damage is also usually followed by injuries to soft tissues such as muscles, joints, and tendons. Along with the increasing number of bone damage cases, one of the recommended therapies is to replace the lost bone or what is commonly referred to as a bone graft. Bone graft is a form of bone repair that is commonly used by clinicians from various disciplines, such as dentists for periodontal regeneration, also used for skull damage and facial surgery, spinal surgery, and of course applications in the orthopedic field [1], [2].

The use of bone graft using materials made from animals is known as the xenograft technique. In this technique, according to Puspa and Asmi [2], cow bones are generally used as the main raw material. However, with the development of other biological alternatives, there is increasing interest in the development of other biological sources for this bone graft. In the past few decades, various allografts and other synthetic grafts have also been developed, including demineralized bone matrix, collagen, calcium phosphate (hydroxyapatite [HA] and b-tricalcium phosphate [b-TCP]), ceramics, calcium sulfate, and biodegradable polymer [3].

$\mathrm{HA}$ is a calcium phosphate compound and is a major constituent of bone tissue. Many bone graft materials use $\mathrm{HA}$ as the main ingredient. HA can be produced from a variety of sources both human, animal, and inorganic substances. Many studies have shown satisfactory results regarding bone graft material from these sources. However, commercially available products, including deproteinized bone from bovine, are very expensive. For extensive bone defect reconstruction, the cost of this high material graft is often a problem. Therefore, it is necessary to develop a bone graft material that is cheap and safe [4], [5], [6].

One of the natural sources of calcium is derived from eggshell. This eggshell is a composite 
material containing calcium carbonate (94\%), calcium phosphate (1\%), organic material $(4 \%)$, and magnesium carbonate $(1 \%)$. Every day millions of tons of eggshells are produced as biological waste around the world, so processing this eggshell waste into HA is very beneficial from various points of view [4], [5], [6].

The aim of this systematic review was to evaluate studies on the effectiveness of eggshells to improve the regeneration of human bone compared to studies with bovine bone graft.

\section{Materials and Methods}

The method used for this article was a systematic review. Systematic review aimed to reduce the bias of research results by identifying, assessing, and synthesizing all researches on a particular topic. The sample selection method was carried out, as shown in Figure 1. Central scientific research databases such as PubMed and Cochrane were accessed using keywords such as ("bone loss" OR "defect" OR "bone defect") AND ("autograft" OR "allograft" OR "bone substitute") AND "xenograft" AND ("eggshell" OR "bovine"). The method used was based on the PRISMA method (Figure 1). We used experts to analyze the database and to do critical appraisal to the researches that we obtained.

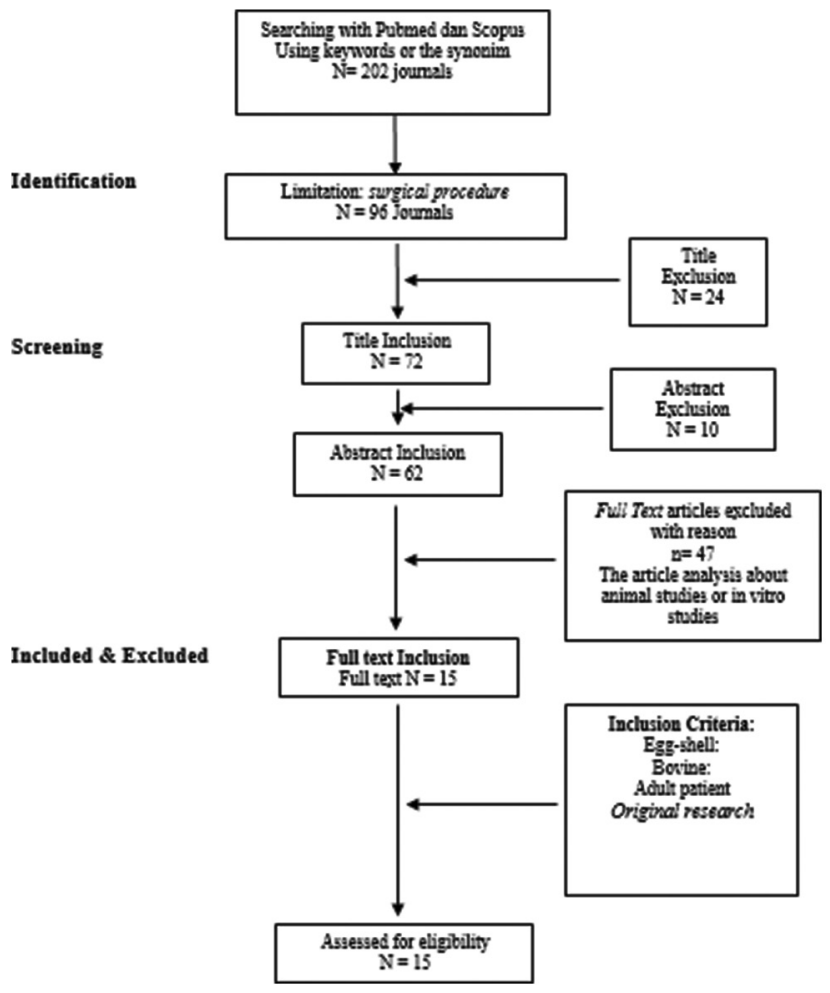

Figure 1: PRISMA flow diagram

\section{Results}

The initial search obtained 202 articles that were reduced to 96 using the limitation surgical procedure. These articles got titles and abstracts screening and led to the exclusion of 34 articles as criteria of exclusion from Figure 1. Then, the reviewer tried to retrieve the whole text from the rest 62 articles, but only 15 papers have the whole text paper. The reviewer systematically analyzed the remaining 15 papers (Table 1 ).

\section{Discussion}

After reviewing all of the obtained studies, we found that bone graft using eggshells can improve the bone regeneration process. Eggshells are a great source of calcium as a dietary supplement. Eggshells are also used as a matrix for bone formation in animal models. Recently, eggshells have been used in various experimental studies to assess their bone formation ability. Eggshell-derived HA/eggshell-derived HA (EHA) appears to be a promising graft material with excellent properties in grafting with various techniques. In this study, what will be discussed is the efficiency of using eggshells whether has a good outcome in terms of bone regeneration or not [5], [6], [7], [8].

EHA is a bone graft that has the potential to produce promising results. In this study, a sample of 10 patients was given a bone graft after dental extraction surgery. Evaluations carried out for 1 week, 1 month, 2 months, and 3 months showed significant differences in bone density at all time intervals $(p<0.05)$. Thus, EHA appears to be a promising bone graft with excellent properties for grafting [6]. When compared between EHA and synthetic hydroxyapatite (SHA), the bone formation patterns different at the $2^{\text {nd }}$ month interval which may be related to early or late resorption of graft particles. From month 1 to month 6 , the bone formation patterns in the SHA and EHA groups remained the same $(p>0.05)$. No significant difference $(p>0.05)$ was found when comparing the mean bone density between SHA and EHA at month 1 and month 6 , which proved that EHA had an outcome similar with the control group [7].

Theuse ofeggshell-derived nanohydroxyapatite (EnHA) showed that bone formation occurred at months 1,3 , and 6 and did not show a significant difference with the control group ( $p>0.05$ ). The eggshell group showed that more than $80 \%$ of the trabecular bone had formed at the final evaluation compared to the control group where only half of the bone healed in the trabecular pattern [8]. The study about application of EHA also made comparisons of radiological evaluation 
Table 1: Result of systematic review about eggshell bone graft and bovine bone graft

\begin{tabular}{|c|c|c|c|c|c|}
\hline Year of publication & $\begin{array}{l}\text { Number } \\
\text { of cases }\end{array}$ & Surgical procedure & Bone graft & Control & Results \\
\hline Kattimani et al., 2014 [5] & 10 & Dental extraction & EHA & No bone graft & Increase bone density for 3 months \\
\hline Kattimani et al., 2016 [6] & 10 & Cystectomy & EHA & SHA & $\begin{array}{l}\text { Increase bone density and bone } \\
\text { formation completed in } 6 \text { months }\end{array}$ \\
\hline Kattimani et al., 2019 [7] & 12 & Third molar extraction & EnHA & No bone graft & Bone formation completed in 6 months \\
\hline Kattimani et al., 2019 [8] & 20 & Apicectomy & EHA & NM & Bone healing in 8 weeks \\
\hline Kattimani et al., 2019 [9] & 11 & Dental extraction & EHA with PRF & NM & $\begin{array}{l}\text { Peningkatan bone density selama } \\
24 \text { minggu }\end{array}$ \\
\hline Munhoz et al., 2012 [10] & 39 & Third molar extraction & Bovine (Gen-tech) & No bone graft & Increase bone density for 6 months \\
\hline Melo et al., 2020 [11] & 20 & Third molar extraction & IBB & No bone graft & Increase bone density for 2 months \\
\hline Munhoz et al., 2011 [12] & 20 & Cystectomy & Bovine (Gen-tech) & No bone graft & Increase bone density for 6 months \\
\hline Bahammam, 2016 [13] & 33 & Corticotomy & Bovine-derived xenograft & Bone graft bioactive glass & Increase bone density for 9 months \\
\hline Kattimani et al., 2014 [4] & 12 & Cystectomy & Bovine-derived xenograft & No bone graft & Increase bone density for 6 months \\
\hline $\begin{array}{l}\text { Kang-mi pang et al., } \\
2017 \text { [15] }\end{array}$ & 10 & Dental extraction & Anorganic bovine bone & $\begin{array}{l}\text { Autogenous tooth graft } \\
\text { material }\end{array}$ & Bone formation completed \\
\hline $\begin{array}{l}\text { Shirmohammadi et al., } \\
2014 \text { [16] }\end{array}$ & 10 & $\begin{array}{l}\text { Sinus floor } \\
\text { augmentation }\end{array}$ & Bovine & NM & Forming of sinus floor augmentation \\
\hline Ferracini et al., 2019 [17] & 34 & $\begin{array}{l}\text { Tibia fracture } \\
\text { operation }\end{array}$ & Xenohybrid bovine bone & NM & $\begin{array}{l}\text { VAS score decrease and positive } \\
\text { outcome }\end{array}$ \\
\hline Rosito et al., 2010 [18] & 26 & Total hip arthroplasty & Bovine & Human graft & Positive outcome \\
\hline Wen-chi tsai, 2010 [19] & 33 & $\begin{array}{l}\text { Tibia fracture } \\
\text { operation }\end{array}$ & Bovine hydroxyapatite & NM & $\begin{array}{l}\text { Bone healing with high-quality fusion } \\
\text { after 6-12 months }\end{array}$ \\
\hline
\end{tabular}

EHA: Eggshell-derived hydroxyapatite; EnHA: Eggshell-derived nanohydroxyapatite; NM: Not mentioned; PRF: Platelet-rich fibrin.

of bone healing at different time intervals (1 month vs. 4 months, 4 months vs. 8 months, 8 months vs. 12 months, and 12 months vs. 24 months). The use of eggshell on cystic defect during apicectomy in the time interval showed a significant difference between time intervals $(p<0.05)$. On socket use with eggshell and platelet-rich fibrin (PRF), $73.91 \%$ of sockets recovered in a trabecular pattern, while the other $26.09 \%$ were found with the present ground-glass. Histological evaluation reveals bone regeneration at the socket. Comparison of bone density in the socket implanted group with nanohydroxyapatite (eggshell) and PRF at weeks 1,12 , and 24 showed a significant increase in bone density $(p<0.05)[8]$.

Based on the analysis above, it can be said that the eggshell containing HA can produce complete bone regeneration in dental growth or result in an increase of bone density equal with the control group in the grafted tooth area. Thus, the use of eggshells is efficient in the process of bone regeneration.

\section{Difference between eggshell-derived bone graft and bovine in terms of human bone regeneration}

From several result studies, complete bone formation has occurred with usually trabecular formation at the 6th month. Hence, the 6th month is a perfect time to compare bone density between eggshell and bovine bone graft. The rapid regeneration of bone in the bone graft occurs due to increased selective adsorption of adhesion proteins and growth factors by $\mathrm{HA} / \mathrm{HA}$, which stimulates osteoblast adhesion and bone deposition through ion release. Several studies showed insignificant differences in bone density between eggshellderived HA bone graft and synthetic HA bone graft $(p<0.05)$. In the use of nanohydroxyapatite from eggshell, nano-HA can be used for preparation of composite materials as a substrate. Both density and visual characteristics can be selected as the standard method for evaluation of bone healing which provides insight into the healing of bone graft administration in an economical manner [9].

When looking at the bone density between eggshell and bovine, the average bone density formed in the 6th month with eggshell is 160.90 and on bovine is 166.70 [7], [8], [9]. However, when comparing the 1st month, the average result of bone density owned by eggshell is 121.65 and the bovine is 155.60 . From the results above, the best bone density is owned by bovine when compared to eggshell in the 1st, 2nd, and 6th months. From the comparison with the control group that was not given a bone graft, that in the majority of the eggshell studies showed that there was no significant difference, the bovine study showed there was a significant difference compared to the control ( $p$ $<0.05$ ). However, research with bovine as a bone graft does not use $100 \%$ bovine with HA but uses branded bone grafts such as bio-Oss or Gen-tech which have other compositions in accelerating bone regeneration compared to eggshell which is $100 \%$ processed directly to get its own HA. Bovine itself has been studied in human bones and has a good outcome and suitable as a bone graft in orthopedic surgery. From an economic point of view, eggshell itself has its own advantages because it is easy to obtain compared to bovine. Although the bone density possessed by bovine is higher than eggshell, there is no significant difference regarding the bone regeneration. Hence, with the ability to increase bone regeneration, having bone density which is almost the same as when using bovine as bone graft, easy to produce and inexpensive, made the eggshell bone graft has its own advantages [10], [11]

\section{Conclusion}

Bone defect or bone damage is a serious condition that occurs after a pathological process has 
damaged vital components of the bone. Bone damage can be caused by various incidents such as trauma, disease (osteoporosis and osteosarcoma), or surgery such as tumor tissue removal. With the increasing number of cases of bone damage, one of the recommended therapies is to replace the lost bone or what we called as a bone graft. One of them is EHA bone graft. Eggshellderived $H A$ has been studied and compared with synthetic HA in human maxillary bone cystic defects resulting from apicoectomy. The osteoinductive nature of nanocrystalline HA can stimulate bone regeneration. Meanwhile, eggshell-derived HA is hydrophilic and can absorb surrounding fluids and blood, so it is easier to arrange and place in the operating area.

This study analysis used a systematic review method regarding the outcome of studies that use the eggshells as bone graft compared to bovine bone graft, obtained from 15 articles selected after going through the identification, screening, and inclusion and exclusion criteria processes. It can be concluded that eggshellderived $\mathrm{HA}$ can produce complete bone regeneration in dental growth or produce an increased bone density in proportion to the control group in the grafted tooth area, especially after 6 months. However, when the eggshell compared to the efficiency of bovine in terms of bone regeneration, bovine has more advantage regard the bone density. Eggshell itself has the advantage of being more economical and easier to obtain compared to bovine. Overall, there is no significant difference between eggshell as a bone graft and bovine regarding bone regeneration, so the eggshell bone density outcome also almost the same with bovine as the bone graft.

\section{References}

1. Gruskin E, Doll BA, Futrell FW, Schmitz JP, Hollinger JO Demineralized bone matrix in bone repair: History and use. Adv Drug Deliv Rev. 2012;64(12):1063-77. https://doi.org/10.1016/j. addr.2012.06.008

Author Query???

AQ2: Kindly check the references citation 12-19.

\section{PMid:22728914}

2. Adi Puspa K, Asmi D. Synthesis and characteristic of biocheramic hydroxyapatite from bovine. Teor Apl Fis. 2014;2(2):125-30.

3. Kwon B, Jenis LG. Carrier materials for spinal fusion. Spine J. 2005;5(6):S224-30.

4. Lee SW, Balázsi C, Balázsi K, Dhyun S, Kim HS, Kim CH, et al. Comparative Study of hydroxyapatite prepared from seashells and eggshells as a bone graft material. Tissue Eng Regen Med. 2014;11(2):113-20. https://doi.org/10.1007/s13770-014-0056-1

5. Kattimani VS, Chakravarthi PS, Kanumuru NR, Subbarao VV, Sidharthan A, Kumar TS, et al. Eggshell derived hydroxyapatite as bone graft substitute in the healing of maxillary cystic bone defects: A preliminary report. J Int Oral Health. 2014;6(3):15-9. PMid:25083027

6. Kattimani V, Lingamaneni KP, Chakravarthi PS, Sampath Kumar TS, Siddharthan A. Eggshell-derived hydroxyapatite: A New Era in bone regeneration. Med (United States). 2016;95(3):112-7. https://doi.org/10.1097/ scs.0000000000002288

PMid:26674907

7. Kattimani VS, Lingamaneni KP. Natural bioceramics: Our experience with changing perspectives in the reconstruction of maxillofacial skeleton. J Korean Assoc Oral Maxillofac Surg. 2019;45(1):34-42. https://doi.org/10.5125/jkaoms.2019.45.1.34 PMid:30847295

8. Kattimani V, Lingamaneni KP, Yalamanchili S, Mupparapu M Use of eggshell-derived nano-hydroxyapatite as novel bone graft substitute-a randomized controlled clinical study. J Biomater Appl. 2019;34(4):597-614. https://doi.org/10.1177/0885328219863311 PMid:31324126

9. de Melo DG, de Santana Santos T, Sehn FP, de Oliveira E Silva ED, Martins-Filho PR, Dourado AC. Evaluation of inorganic bovine bone graft in periodontal defects after third molar surgery. Ann Maxillofac Surg. 2015;5(2):198-202. https:// doi.org/10.4103/2231-0746.175765

PMid:26981470

10. Shirmohammadi A, Roshangar L, Chitsazi MT, Pourabbas R, Faramarzi M, Rahmanpour N. Corrigendum to comparative study on the efficacy of anorganic bovine bone (bio-oss) and nanocrystalline hydroxyapatite (ostim) in maxillary sinus floor augmentation. Int Sch Res Not. 2017;2017:1. https://doi. org/10.1155/2017/7258513

11. Ferracini R, Bistolfi A, Garibaldi R, Furfaro V, Battista A, Perale G. Composite xenohybrid bovine bone-derived scaffold as bone substitute for the treatment of tibial plateau fractures. Appl Sci. 2019;9(13):1-11. https://doi.org/10.3390/app9132675 